\title{
Relationship between anthropometric characteristics and playing position in youth soccer
}

\author{
Angela Notarnicola ${ }^{1,2}$ \\ Giuseppe Maccagnano ${ }^{1,2}$ \\ Alessandro Chierico ${ }^{2}$ \\ Silvio Tafuri 1,3 \\ Biagio Moretti ${ }^{1,2}$
}

${ }^{1}$ Course of Motor and Sports Sciences, Department of Medical Sciences of Basis, Neurosciences and Organs of Sense, Faculty of Medicine and Surgery, University of Study of Bari, Bari, Italy

2 Orthopedics Section, Department of Medical Sciences of Basis, Neurosciences and Organs of Sense, Faculty of Medicine and Surgery, University of Study of Bari, General Hospital, Bari, Italy

3 Department of Biomedical Sciences and Human Oncology, Faculty of Medicine and Surgery, University of Study of Bari, General Hospital, Bari, Italy

Corresponding author:

Angela Notarnicola

UOC Ortopedia e Traumatologia

Piazza Giulio Cesare 11

70124 Bari, Italy

Tel.: 0805592938

E-mail: angelanotarnicola@yahoo.it

\section{Summary}

Introduction: There are four principles positions in soccer: goalkeepers, defenders, midfielders and forwards. Midfielders run longer distances than the others; defenders dribble shorter distances, whilst forwards perform significantly more sprints. These different performance requirements could be better achieved when supported by optimal physical characteristics. Accordingly, forwards are generally leaner than midfielders, defenders, and goalkeepers and the muscle percentage is higher in the forwards compared to the midfielders and the goalkeepers. These data are related to adults and adolescents, while up to now there are no data on pre-adolescent players. The purpose of the study is to verify if the anthropometric characteristics could influence the assignment of the position for soccer players aged 12 to 14 years.

Methods: We designed an observational study in order to measure the anthropometric parameters of 36 under-14 players: 11 defenders (DF); 13 midfielders (MF); 12 forwards (FW).

Results: We found that the DFs were the heaviest $(58,6 \pm 7,9 \mathrm{~kg})$ and tallest $(165,7 \pm 7,8 \mathrm{~cm})$ players and had the two greater measures (waist circumference: $71,4 \pm 7,0 \mathrm{~cm}$; waist diameter: $74,5 \pm 5.1$ $\mathrm{cm})$. The FWs were the lightest $(49,9 \pm 6,8 \mathrm{~kg})$ and with the smallest waist $(63,6 \pm 4,0 \mathrm{~cm})$ and pelvis circumferences $(67,6 \pm 4.7 \mathrm{~cm})$, whilst the midfielders were the shortest $(157,2 \pm 9,3 \mathrm{~cm})$. All the players underwent three tests to measure the main physical capacities involved to soccer: sprint test, Nittoli skip test and Sargent jump test. No correlation emerged between the roles and physical performances.

Conclusion: In soccer players between 12 and 14 years old, we did not find any correlation between the position and physical performance. In this age group the assignment of the position of play is not yet influenced by the anthropometric characteristics of the player, probably because in these years the weight, height and body circumferences are rapidly changing. In the following years, when the constitutional characteristics are stabilized, they will be valorized and used as a starting point to optimize performances.

Level of evidence: IV.

KEY WORDS: soccer, anthropometric measure, skill, ability.

\section{Introduction}

Soccer is one of the most popular games in the world. Its performance requires technical precision, speed $^{1}$ and endurance ${ }^{2}$. Four principal different positions are present in soccer: goalkeepers, defenders, midfielders and forwards ${ }^{3-6}$. Each position corresponds to a different workload during the match: midfielders run longer distances than the other positions ${ }^{7-9}$; defenders dribble shorter distances than the others do, whilst forwards perform significantly more sprints than defenders or midfielders do ${ }^{10-12}$. In professional players there emerged a relationship between the position and the anthropometric parameters such as body mass, height, and body mass index $(\mathrm{BMI})^{13}$. In fact, a different body structure influences the physical and sport performance: forwards are generally leaner than midfielders, defenders, and goalkeepers and the muscle percentage is higher in 
the forwards compared to the midfielders and the goalkeepers.

On the basis of this hypothesis, it should be interesting to verify how the anthropometric and sports performance parameters may influence the selection and definition of the position of play in the young players $^{14,15}$. In fact, in different sports, in particular athletics, rowing and gymnastics, specific programs have been developed 16,17 . Until now, as regards soccer, the definition of the position is attributed empirically ${ }^{18}$. Consequently, the aim of this study was to establish the anthropometric and physiological profiles of young soccer players according to their playing positions, in order to facilitate the elaboration of a template describing their profile which can be used by coaches and technical staff. Our objective is also to determine which anthropometric characteristics are the most relevant in the selection process of soccer players for each position.

\section{Materials and methods}

We conducted an observational study, with the sequential recruitment of young males belonging to the youth sectors of two sports clubs. The research was conducted ethically according to international standards and as required by the journal ${ }^{19}$. The inclusion criteria were: age between 12 and 14 years; role as defender, midfielder and forwards; continuous activity for at least 2 years. The exclusion criteria: previous injuries of the lower limbs in the last 6 months. The young soccer players who had followed the same soccer-specific training in the last three months. Players trained for 90 minutes 3 times per week and played a match during the week-end. Each training season generally consisted of a 15-minute warm-up, 20-minute technical training, 20-minute tactical training, 30-minute simulated competition, and a 5-minute cool-down. Within the team, all players of different positions trained together. All players and their parents were properly informed of the nature of the study and they signed an informed consent document according to the Declaration of Helsinki and the protocol was fully approved by the Clinical Research Ethics Committee.

For each of the subjects recruited, a data collection form was compiled including personal data (in particular, age was reported in years and months at the time of enrollment), anthropometric measurements and the results of the tests relating to physical ability. We encountered no refusal and the measurements were performed by the same person to minimize inter-observer variability. The used morphological measurements were: body mass (weight) (kg) was measured twice $\left(\right.$ Seca ${ }^{\circledR} 861$ scales) with the athlete barefoot and in light clothing; height $(\mathrm{cm})$ was measured twice, using a wall stadiometer (Kawe ${ }^{\circledR} 222$ ), with the athlete barefoot and upright and with the sagittal midline touching the back board.

Waist circumference (WC) $(\mathrm{cm})$ was measured at 2 $\mathrm{cm}$ below the navel at the end of a normal expiration. Waist diameter $(\mathrm{cm})$ was measured at the pelvis at the widest points, at the end of a normal expiration. Wrist circumference $(\mathrm{cm})$ was measured using a flexible tape measure positioned over the Lister tubercle of the distal of radius and over the distal of ulna when subjects were in a sitting position. Elbow circumference $(\mathrm{cm})$ was measured at the elbow. Thigh proximal circumference $(\mathrm{cm})$ was measured at the greatest dimension of the calf. Thigh distal circumference (cm) was measured at $15 \mathrm{~cm}$ above the upper edge of the patella. All these circumferences were measured two times at the level of the dominant limb using a flexible tape (Amtech P1800)

Body mass index $\left(\mathrm{kg} / \mathrm{m}^{2}\right)$ was calculated as weight in kilograms divided by the square of the height in meters. WHtR (waist-to-height ratio) was calculated by dividing waist circumference in centimeters by height in centimeters.

For the evaluation of performance and physical ability, the sprint (s), Nittoli e Sargent tests were administered. Each athlete performed these three tests in different days, to avoid any fatigue effect.

\section{$40 \mathrm{~m}$ sprint (40S)}

Sprinting performance was assessed using a sprint over a distance of $40 \mathrm{~m}^{20}$. The test was performed from a standing start and measured by means of infrared photocells (Globus $\AA$, Codogné, Italy). The photocells have to be placed at 0 and 40 meters in a straight line and on a flat and well-grassed area, preferably in the absence of favorable or unfavorable winds. After proper warming up, the subjects have to shoot from a stationary position $1 \mathrm{~m}$ ahead of the photocell placed at $0 \mathrm{~m}$ and to run for $40 \mathrm{~m}$ as fast as possible. The stopwatch starts as soon as the first photocell is crossed and stops when the subject passes the photocell placed at $40 \mathrm{~m}$. The best result obtained in two tests is recorded.

\section{Nittoli Skip test ${ }^{21}$}

Consists of a knee-high run race (thigh always above the horizontal line) for 120 seconds, with the frequency of 2 foot placements per second. A pause for 1 minute is fixed and for the following 30 seconds the heart rate (number of pulses in 30 seconds) is checked. For the evaluation, we performed the same procedure of the IRI (Immediate recovery index), comparing the results in the table below. A single test was performed.

\section{exercise time in sec. $x 100$}

\section{IRI TEST:}

\section{$5.5 \times$ recorded pulse rate}

Index of physical efficacy:

- over $80=$ excellent,

- between 80-70 = good

- between 70-60 = sufficient,

- between 60-50 = low,

- under 50 = insufficient. 


\section{Sargent Jump test ${ }^{22}$}

The athlete warms up for 10 minutes. The athlete chalks the end of his/her finger tips. The athlete stands side onto the wall, keeping both feet remaining on the ground, reaches up as high as possible with one hand and marks the wall with the tips of the fingers (M1). The athlete from a static position jumps as high as possible and marks the wall with the chalk on his fingers (M2). The assistant measures and records the distance between $M 1$ and $M 2$. The athlete repeats the test 3 times. The assistant calculates the average of the recorded distances and uses this value to assess the athlete's performance.

All measures were carried out by two independent observers and in case of differences in the evaluation, the measure was repeated.

The compiled forms were inserted into a database created with Google Drive software and data analysis was performed with Microsoft Office Excel and STATA MP12 software. The continuous variables were expressed as means with the indication of standard deviations. The categorical variables were expressed as proportions. In order to compare the means between groups, the analysis of normality was carried out and a normalization model was developed for non-normal variables. Average value of normal or normalized variables were compared by ANOVA and Bonferroni correction was used where consistent. Non-normalizable variables were analyzed with Kruskal-Wallis tests. For the comparison of proportions, the chi-square test was used. For all the tests used, a value of $p<0.05$ was considered significant.

\section{Results}

The study sample consists of 36 subjects, all male, of which 13 were midfielders group $(36.1 \%), 11$ defenders $(30.6 \%)$ and 12 forwards $(33,3 \%)$. The results of the epidemiological, anthropometric evaluations and the tests administered for each group are showed in Table I. The average weight in the sample is $53.4 \pm$ $8.9 \mathrm{~kg}$. The analysis of variance with correction of Bonferroni shows a statistically significant difference between the three groups $(\mathrm{F}=3.4 ; p=0.046)$. Moreover, there emerges a statistically significant difference between the group of defenders and the forwards $(\mathrm{F}=8.8, p=0.049)$.

The average height of the sample is $159.8 \pm 9.0 \mathrm{~cm}$; there emerges a significant difference by comparison of the groups $(F=3.9, p=0.029)$. The Bonferroni correction shows a statistically significant difference between defenders and midfielders ( $F=8.5 ; p=0.05)$. The mean diameter of waist in the recruited subjects is $66.9 \pm 6.2 \mathrm{~cm}$, with a significant difference by comparison of the groups $(\mathrm{F}=5.6, p=0.01)$. Bonferroni correction shows a statistically significant difference between the defenders and the forwards ( $F=6.0$; $p=0.01)$. The mean hip diameter in the recruited subjects is $70.4 \pm 5.6 \mathrm{~cm}$, with a statistically significant difference by comparison of the group ( $F=6 ; p=0.01)$. Bonferroni test shows a statistically significant difference between the group of defenders and that of the forwards $(F=7 ; p=0.01)$ and between the group of defenders and that of the midfielders ( $F=6 ; p=0.049)$. No differences in sprint, Nittoli skip and Sargent Jump tests have been noted dividing the sample per group (Tab. II).

\section{Discussion}

The results of our work allow us to study the relationship between the playing position, the anthropometric characteristics and the physical performance in a population of young soccer players. Until now, the data available regarded adult athletes. We found a differences in the groups for position and anthropometric measurements, such as body mass $(p<0.05)$, height $(p=0.05)$, and waist circumference $(p=0.01)$

Table I. Anthropometric variables, per group. The mean value and standard deviation of variables analyzed for each of the three groups. WHtR, waist-to-height ratio.

\begin{tabular}{|c|c|c|c|c|}
\hline Variable & Midfielders & Defenders & Forwards & $p$-value \\
\hline Age (years) & $12.8 \pm 0.7$ & $13.4 \pm 0.7$ & $13.3 \pm 0.8$ & 0.145 \\
\hline Weight (kg) & $52,2 \pm 9,7$ & $58,6 \pm 7,9$ & $49,9 \pm 6,8$ & 0.046 \\
\hline Height $(\mathrm{cm})$ & $157,2 \pm 9,3$ & $165,7 \pm 7,8$ & $157,3 \pm 7,7$ & 0.029 \\
\hline Waist circumference (cm) & $66,3 \pm 5,2$ & $71,4 \pm 7,0$ & $63,6 \pm 4,0$ & 0.01 \\
\hline Waist diameter $(\mathrm{cm})$ & $69,4 \pm 5,1$ & $74,5 \pm 5.1$ & $67,6 \pm 4.7$ & 0.01 \\
\hline Wrist circumference $(\mathrm{cm})$ & $16,7 \pm 1,2$ & $17,5 \pm 0.8$ & $16,7 \pm 0.7$ & 0.763 \\
\hline Elbow circumference $(\mathrm{cm})$ & $21,3 \pm 1,4$ & $22,7 \pm 2,5$ & $21,3 \pm 1,6$ & 0.135 \\
\hline Thigh proximal circumference $(\mathrm{cm})$ & $46,5 \pm 6,1$ & $51,5 \pm 6,7$ & $46,9 \pm 5.3$ & 0.378 \\
\hline Thigh distal circumference $(\mathrm{cm})$ & $36,3 \pm 5,6$ & $40,9 \pm 7,1$ & $37,8 \pm 3,9$ & 0.235 \\
\hline Body mass index $\left(\mathrm{kg} / \mathrm{m}^{2}\right)$ & $21,0 \pm 3$ & $21,6 \pm 1.9$ & $20,1 \pm 2$ & 0.337 \\
\hline WHtR & $0,4 \pm 0$ & $0,4 \pm 0$ & $0,4 \pm 0,1$ & 0.197 \\
\hline
\end{tabular}


Table II. Results of performance tests, per group.

\begin{tabular}{lllll}
\hline Variable & Midfielders & Defenders & Forwards & $p$-value \\
\hline 40 m sprint (sec) & $7,3 \pm 0,5$ & $7.4 \pm 0,5$ & $7,1 \pm 0.4$ & 0.378 \\
Nittoli skip test (IRI) & $55,9 \pm 11,7$ & $49-3 \pm 5.3$ & $53,3 \pm 4,9$ & 0.154 \\
Sargent jump test $(\mathrm{cm})$ & $34,6 \pm 6,7$ & $39 \pm 5,3$ & $37,8 \pm 6,6$ & 0.219 \\
\hline
\end{tabular}

and hips $(p<0.05)$. Specifically, DFs are the heaviest and tallest players and with the two major circumferences, and forwards are the lightest and with the lowest waist circumference and hips, and the midfielders are the shortest. These results are generally coherent with those found in adult professional footballers and show that taller and heavier players are better suited to playing in the roles of goalkeeper $(G K)$ and DF, while the shorter and lighter ones in the position of midfielders or defenders ${ }^{13}$. Our results are also in accordance with the data reported in a case series of young players aged $14-21^{13,14}$. In the literature, the analysis of body composition and fat mass showed that forwards were leaner than midfielders, defenders, and goalkeepers ${ }^{14}$. In contrast, muscle percentage was higher in the forwards compared to the midfielders and the goalkeepers.

In our population we did not find any correlation between the position and physical performance, contrary to what occurs in players above the age of 14 , where forwards are the best performers in all the physiological tests, including endurance, velocity, agility and power. In the selection process, agility and the jump tests were the most discriminating for forwards. In contrast, agility, height, and endurance were the key factors for midfielders ${ }^{14}$. Our results can be interpreted in relation to the variations that occur in the alternation of the growth stages (proceritas and turgor). In particular, pre-adolescence is an important phase for body growth. In the age group 12-14 years (proceritas II), that we analyzed, there emerges an important increase in body weight and increase in height and weight. In this phase, which is a "black moment for physical activity"4, the physical skills are expressed with greater difficulty than the following phase (turgor III) when, with a slowdown in body growth, it is possible to better express explosive performance, sprint, agility and resistance, all of which are important for specific abilities ${ }^{4,23}$. The lack of statistically significant differences in the physical performance parameters between the various positions is in accordance with the hypothesis that body growth compromise the expression of their skills in all subjects. Abilities such as speed, agility, endurance are important during a football match. The preparation and the sport training, as well as the alternation with periods of turgor (golden period of motor skills), allows enhanced expression of these abilities, justifying the subsequent appearance of differences in relation to the position, with a bias favoring the forwards. On the other hand, we did not exclude the possibility that, by selecting the young players in relation to their anthropometric characteristics, we could indirectly influence physical and sports performance. In fact, to direct the leaner and stronger players to the role of forwards could also determine better performances of agility and power. Recruiting the tallest players to the role of midfielders could guarantee greater agility and endurance. The defenders are with leaner body, greater muscle mass in the lower limbs and muscle power and these characteristics allow them to jump higher to block goal-bound shots. To confirm a correlation between the anthropometric characteristics and physiological performance, in a previous work on young U14 players, the Authors reported a relationship between of weight with speed and sprint and height with jump, sprint and resistance ${ }^{13}$. The results of our study confirm what the coaches have always practiced arbitrarily, that is, to direct the young players to a position more in relation to their anthropometric characteristics than to their tactical and technical performances ${ }^{24,25}$.

A weak point of the study is the lack of data regarding the role of goalkeepers, because it was not possible to find a large number of participants. The second weak point is the lack of comparison with another age group, which would have allowed us to verify the subsequent appearance of differences between the roles as regards physical performance. Future studies, including longitudinal studies, will allow us to improve our knowledge regarding the factors that allow us to identify not only the most suitable position, but also the potential talent. The strong point of the study is the age class which until now has not been analyzed. A more detailed profile of the anthropometric characteristics and physical performances could be developed for each position, in relation to age, which could allow to choose the best position for the young player.

Based on our experience, we confirm the coaches' habit of identifying the role of players in relation to their anthropometric characteristics in different age groups. We suggest paying attention to very young players, in particular at the stages of procreates, in when the important body growth temporarily compromises physical abilities, in order to avoid an improper selection of position based on physical performance.

\section{Conflicts of interest}

The Authors certify that there is no conflict of interest with any financial organization regarding the material discussed in the manuscript. 


\section{Acknowledgments}

The Authors thank Brian John Molloy B.A. for language revision.

\section{Author contributions}

According to literature ${ }^{25}$ the Author contributions are as follows: AN drafted the article; GM gave substantial contributions to interpretation of data for the study; AC gave substantial contributions to the acquisition, analysis, and interpretation of data for the study; ST revised the article critically for important intellectual content; BM finally approved the version of the article to be submitted.

\section{References}

1. Faude $\mathrm{O}$, Koch $\mathrm{T}$, Meyer T. Straight sprinting is the most frequent action in goal situations in professional football. J Sports Sci. 2012;30(7):625-631.

2. Castagna C, Impellizzeri F, Cecchini E, Rampinini E, Alvarez JC. Effects of intermittent-endurance fitness on match performance in young male soccer players. J Strength Cond Res. 2009;23(7):1954-1959.

3. Casajù SJA, Aragone SMT. Estudio cineantropometrico del futbolista profesional espanol. Arc Med Dep. 1997;59:177184.

4. Malina RM, Pena Reyes ME, Eisenmann JC, Horta L, Rodrigues J, Miller R. Height, mass and skeletal maturity of elite Portuguese soccer players aged 11-16 years. J. Sports Sci. 2000;18:685-693.

5. Rienzi E, Drust B, Reilly T, Carter JE, Martin A. Investigation of anthropometric and work-rate profiles of elite South American international soccer players. J Sports Med Phys Fitness. 2000;40:162-169.

6. Wisloff U, Helgerud J, Hoof J. Strength and endurance of elite soccer players. Med Sci Sport Exerc. 1998;30:462-467.

7. Bansgbo J, Norregaard L, Thorso F. Activity profile of competition soccer. Can J Sport Sci. 1991;16:110-116.

8. Wisloff U, Helgerud J, Hoof J. Strength and endurance of elite soccer players. Med Sci Sport Exerc. 1998;30:462-467.

9. Cometti G, Maffiuletti NA, Poussion M, Chatard J, Mafulli N Isokinetic strength and anaerobic power of elite, subelite and amateur soccer players. Int J Sports Med. 2001;22:45-51.

10. Di Salvo V, Baron R, Tschan H, Calderon Montero FJ, Bachl
N, Pigozzi F. Performance characteristics according to playing position in elite soccer. Int J Sports Med. 2007;28:222-227.

11. Di Salvo V, Gregson W, Atkinson G, Tordoff P, Drust B. Analysis of high intensity activity in Premier League soccer. Int $J$ Sports Med. 2009;30:205-212.

12. Rampinini E, Coutts AJ, Castagna C, Sassi R, Impellizzeri FM. Variation in top level soccer match performance. Int J Sport Med. 2007;28:1018-1024.

13. Wong PL, Chamari K, Dellal A, Wisløff U. Relationship between anthropometric and physiological characteristics in youth soccer players. J Strength Cond Res. 2009;23:1204-1210.

14. Gil SM, Gil J, Ruiz F, Irazusta A, Irazusta J. Physiological and anthropometric characteristics of young soccer players according to their playing position: Relevance for the selection process. J Strength Cond Res. 2007;21:438-445.

15. Gravina L, Gil SM, Ruiz F, Zubero J, Gil J, Irazusta J. Anthropometric and physiological differences between first team and reserve soccer players aged $10-14$ years at the beginning and end of the season. J Strength Cond Res. 2008;22:1308-1314.

16. Bourgois J, Claessens AL, Vrijens J, Philippaerts R, Van Renterghem B, Thomis M, et al. Anthropometric characteristics of elite male junior rowers. Br J Sport Med. 2000;34:213217.

17. Hoare DG, Warr CR. Talent identification and women's soccer: an Australian experience. J Sport Sci. 2000;18:751-758.

18. Reilly T, Bangsbo J, Franks AM. Anthropometric and physiological predispositions for elite soccer. J Sports Sci. 2000;18(9):669-683.

19. Padulo J, Oliva F, Frizziero A, Maffulli N. Muscles, Ligaments and Tendons Journal - Basic principles and recommendations in clinical and field science research: 2016 update. MLTJ. 2016;6(1):1-5.

20. Impellizzeri FM, Rampinini E, Castagna C, Bishop D, Ferrari Bravo D, et al. Validity of a Repeated-Sprint Test for Football J Sports Med. 2008;29:899-905.

21. Hood PE, Barnes CA, Gregson W. Realibility of a battery of soccerspecific field test. J Sport Sci. 2002;20:20-21.

22. Sargent DA. The Physical Test of a Man. American Physical Education Review. 1921;26:188-194.

23. Figueiredo AJ, Gonçalves CE, Coelho E Silva MJ, Malina RM. Youth soccer players, 11-14 years: maturity, size, function, skill and goal orientation. Ann Hum Biol. 2009;36(1):60-73.

23. Helsen, WF, Starkes, JL, and VanWinckel, J. The influence of relative age on success and dropout in male soccer players. Am J Hum Biol. 1998;10:791-798.

24. Helsen WF, van Winckel J, Williams AM. The relative age effect in youth soccer across Europe. J Sports Sci. 2005;23(6): 629-636.

25. Padulo J, De Giorgio A, Oliva F, Frizziero A, Maffulli N. I performed experiments and I have results. Wow, and now? MLTJ. 2018 Jan 10;7(3):403-410. 